\title{
Features of the Japanese genre of hokku in the works by $\mathrm{K}$. Utkin
}

\author{
T. Vasilieva* \\ North-Eastern Federal University named after M.K. Ammosov, 677000, 58 Belinsky str., Yakutsk (Republic of Sakha), Russian \\ Federation
}

\begin{abstract}
The paper presents the study of the poetics of the Japanese genre of hokku in the works by the famous Yakut poet, philosopher and culture expert Ksenophont Dmitrievich Utkin. The features of compliance with the canons of Japanese poetry have been identified: adherence to the basic rules and traditions (stylistic, stanza and compositional criteria), aesthetic principles and categories, semantic structure. The national specifics of mastering the genre, which is manifested in the disclosure of the image, sound pattern, and the desire to express the national perception of the world. The study yielded the conclusion that mastering of hokku in Yakut poetry is primarily based on traditional features. The studied examples are close to the typology of the original in terms of formal and compositional principles: the two-part structure of the work, the stanza and syllabic canon. The poet adheres to the thematic features associated with the description of nature, the world and the state of mind of the lyric hero. A typological similarity between the studied hokku and Japanese poetics is observed in adherence to aesthetic principles (yugen, shiori, engo), the use of seasonal words, vagueness, allegory and symbolism. The need for knowledge of the traditional culture brings the works closer to Japanese poetry. Yakut works are characterized by a special rhyme, the role of alliteration and national interpretation of images, and the material and spiritual components of the Yakut worldview.
\end{abstract}

\section{Introduction}

The golden age of any literature, as well as culture in general, is difficult to imagine without contact with the cultures of other peoples, without the perception of their values and achievements. This phenomenon is evidenced by the appearance of borrowed lyrical forms, poems based on foreign literature.

Japanese poetry, primarily tanka, gained fame in Russia in the 1910s. Russian poets either referred this to a 3-4-foot trochee or to the rhythm of a full-syllable elegiac distich [1]. Russian readers are familiar with tanka and hokku in translations into Russian. In recent years, the national poetry of Siberia has shown a rather interesting phenomenon, namely, the synthesis of the traditions of European and Eastern literature. Earlier, the leading position was occupied by the European traditions, mainly Russian, and from the mid-60s and 70 s the focus was on the oriental poetry and its national traditions. For example, there are poems by Japanese poets translated by the Buryat lyric poet D. Ulzytuev, tanka and hokku by $\mathrm{N}$. Nimbuev. In the national literature, the borrowing of any stanza occurs mainly on the basis of traditional features. In such cases, the general spirit of the non-national genre can be observed, which is evidenced, for example, by the entry of tanka into Yakut lyrics. Poets often do not adhere to the canonical syllabic principle of tanka (5-75-7-7). The miniatures of Yakut lyricists are philosophical reflections on nature, which serves as an analogy for the phenomena of life. In these miniatures, reflections are associated with the dialectics of specific phenomena in the life of the author. In the figurative perception of nature, poets reveal the state of mind, which gives a special psychologism to miniatures.

Works of oriental lyrics appear in Yakut literature in the 1970s. These years are significant for Yakut lyrics due to strengthening of its journalism, civic spirit, and the expansion of its meditative and philosophical orientation. This period is also characterized by the search for new value and aesthetic indicators, which led to the active development of genre and stylistic forms of poetry of other peoples. At the same time, literature, enriched and retained the national originality of artistic knowledge of the world and versioning. The creative perception of the experience of world poetry and its impact led to the canonized forms of oriental verse, close to the typology of the original, in works by Yakut poets. During these years, the national poetry was enriched with new lyrical genre forms not only in Yakut, but also in other Russian literature works. In most cases, this process was initially reflected in style and genre imitations and borrowings [2]. According to a number of researchers, this principle of the entry of foreign experience into the national poetic culture is a natural stage [3]. L.S. Mizhit reports that in the poetry of the peoples of Siberia (Khakass, Altai, Buryat, Yakut), tercets are rare

*Corresponding author: vaaperevod@mail.ru 
and not isolated into a separate genre. In the Tuvan poetry, the poems of ozhukdazhy ("hearth stones") are close to the hokku in formal and ideological content. They were formed in the 1980s under the impact of Japanese poetry, but can be distinguished by organization and artistic and aesthetic features. It is also indicated that in the 1990s the Tuvan press published tercets defined by the genre as hokku, but they did not meeting its aesthetic requirements and principles. Thus, it was an attempt of borrowing, which did not receive further development [4].

One of the first versions of oriental genre in Yakut lyrics is the works by the folk poet Semyon Danilov "based on Japanese motives" (author's clarification) included in the collection of poems "Byikaykaanhohoonnor" ("Little Poems", 1973). The works resemble the genre of tanka, which is most widespread in Japanese lyrics. The traditional tanka is a non-rhymed poem of 31 syllables in five lines. The poems in the above collection consist of a different number of lines (from 6 to 13), numbering from 3 to 12 syllables. All this poses a question: what is the similarity between the poems and the Japanese tanka? The typological feature of poems by Semyon Danilov is the similarity with the theme and compositional structure of tanka. The fact that the author does not adhere to the syllabic principle, in our opinion, is the originality of his poetic style. In the works by $\mathrm{S}$. Danilov, sound repetitions, alliteration and rhyme acquire special significance due to the general semantic movement of the poem. Each work features repetitions of similar sounds, repetitions of words, stanza alliteration, rhyming of the final and initial words. Sound pattern in this collection acts as a structural element necessary to reproduce the state of mind of the author. Thus, we can say that "S. Danilov creatively approaches the comprehension and development of foreign images and motives, organically using them in his strong poem" [5]. That was the first experience of Yakut poets to borrow Japanese lyrics. Since 1973, Yakut poets have repeatedly turned to the genre of tanka. The first tercets hokku appeared only in 2006, and this study is focused on the analysis of this poem.

\section{Materials and Methods}

The methodological basis of this study is the systematic investigation of a literary text. In order to identify various manifestations of the author's personality in the textual reality, it is necessary to use a comparative method for the study of works [6].

The comparative historical method helps understand the similarities and differences in the phenomena of verbal and artistic creativity related to different national literature.

The features of hokku in Yakut poetry are investigated based on the analysis of typological convergences (themes, ideas and problems), rhyme, rhythm and composition, in terms of classical canons and national specifics. To identify similarities or differences and determine the national characteristics of poetic forms of foreign literature, we used the methods of verse analysis of rhythm, rhyme and alliteration.

In Yakut literary studies, the issues of literary relations have been the subject of study since the 1940s. It should be noted that these works mainly concerned Russian-Yakut relations and influences at the stage of formation and development of Yakut written literature. In this regard, the work of A A. Ivanov-Kyunde "Artistic forms of Yakut poetry" (1931) is noteworthy, where the system of folk verse and Yakut poetry are considered for the first time in comparison with other systems of versification. A significant contribution to the development of Yakut poetry is N. N. Toburokov's monograph "Problems of comparative poetry (based on the material of Soviet poetry of the Turkic-speaking peoples of Siberia)" (1991), where a comparative typological analysis of the development of the versification of the Turkicspeaking peoples of Siberia is carried out. The study of Yakut poetry in the context of the world literary process is found in A. A. Burtsev's articles "International relations of Yakut literature", "Yakut literature in the context of the world literary space" and in the work "Dialogues in a single space of world literature" (2004). Russian Russian literary relations Problems and aspects of typological similarities and influences are noted in the works of Z. K. Basharina "Interaction of Russian and Yakut literatures" (1992), "Commonwealth of Literatures" (2002) and N. P. Kanaev "Russian-Yakut literary relations" (1965), "From the history of Russian-Yakut literary relations (20-30s)" (1973), some issues are touched upon in the studies of A. A. Bilyukina, D. E. Vasilyeva, M. N. Dyachkovskaya, M. G. Mikhailova, A. N. Myreeva, V. B. Okorokova, M. P. Popova, L. N. Romanova, E. S. Sidorova, etc. In the study of the history of Yakut poetry, the issues of solid forms are considered by P. V. Maksimova in the monograph "Genre typology of Yakut poetry" (2002) and M. P. Popova in the work "Modern Yakut poetry (1980-2000's)" (2007), where descriptions and analysis of forms borrowed from classical European and Eastern poetry are given, which is one of the trends in the development of modern Yakut lyrics [7].

The analysis of these works allows us to conclude that solid forms, including Japanese haiku, as a phenomenon in lyrics are most fully and comprehensively studied in the history of Russian and world literature. In Yakut literary criticism, they are presented, one might say, in the form of a problem statement and as a form of lyrics. Thus, the foundations for further study of haiku are laid in Yakut literary studies, as an example of contact-typological connections of Yakut poetry with world and Russian literature. In this regard, this issue requires further research. This allows us to consider the topic of this work not sufficiently studied and determines the expediency and legitimacy of studying the Japanese genre form of haiku by these methods. 


\section{Results and Discussion}

In Yakut lyrics, the Japanese genre of hokku is represented in the tercets by K.D. Utkin. This poet is Doctor of Philosophy, Professor, the author of famous scientific works on history, ethnography, folklore, philosophy, art and literature; a researcher of the traditional culture of the Sakha people, a propagandist of folk wisdom; the author of five collections of poetry and three literary critical and literary works. In 2006, K.D. Utkin published the collection "SYmeleeh syytyk" ("My Magic Thimble"), which includes three cycles. The choice of the form is substantiated in the introduction, where the author discusses the significance of the impact of foreign literature, borrowings in Yakut poetry, indicating exactly solid forms, such as sonnet, rubai and gazelle. The poet explains his choice by love for native language.

The collection consists of three thematically homogeneous cycles of 88 works. The ideological and thematic orientation is shown by the names of the volumes: "Man", "Life", "Nature", which represent the features of the worldview of a northern man.

The first cycle, "Man", includes 29 poems systematized in the dynamics of the compositionalthematic development of the idea. An original introduction, the main part and the conclusion are the symbolic stages of life.

The first two hokku (introduction) reveal the idea that customs, traditions, and the memory of ancestors passing from generation to generation are an endless connecting thread for the existence of mankind on earth:

Siemmin ataardym - I saw off my grandson Kyyrai khallaan kynattaan, Gave wings to the high sky,

Djolu tuttaran. [8] Happiness is in your hands.

The birth of a person is predetermined, and his life path is determined by time and fate. In life, a person should strive for harmony, which is achieved by virtue, wisdom, and for development. However, he tends to be delusional in the fact that we are all equal and mortal (most of us). After death, the name of a person will remain in his good deeds. The human soul can return to its beginning or continue in descendants, that is, the poet shows the endlessness, the eternal motion of life (conclusion).

Tyynnaah buolammyn It means I live

Tybyyra tyynabyn, As I breathe loudly,

Tokhtuurbun umnan. [8] Forgetting to stop.

The author discusses maturity and wisdom as happiness; the laws of life; true love as support and understanding of each other; beauty that is eternal as a sprout of the future. The author expresses concern and regret that a person has begun to forget about his destiny.

The second cycle, "Life", includes 29 poems. Material and spiritual components are revealed in the perception of the world. These rituals and traditions for the soul (kut) are the peculiarities of the people. The author expresses pain and anxiety that traditions and customs disappear with the old generation, and the new one no longer understands the traditional values. Time flies faster and faster day after day and spares no one and nothing. The deep subtext of the poems confirms that much is predetermined. "However, the people have a choice: to survive or not to survive as an ethnos" [6]. The cycle confirms the general pattern of development: the fate of the culture is the fate of the people.

The poet's thoughts about life are of interest. He defines it as a game in which the role assignment is unknown. Life is a teacher, it teaches in silence and creates a true person, who learns life in struggle and constantly overcomes difficulties and obstacles. The peculiarities of living conditions are the basis of the self-awareness of the people. For example, cold, dark nights make you appreciate the sunlight falling through a small window of the Yakut yurta:

Tynnykpyt kyra. The window is small.

Kun kyyrpakhyn kemchiliir. There is little light from the sun.

Yerete turar. [8] Teaches.

The third cycle, "Nature", includes 30 works, where the author discusses the perception of the world in relation to the symbols of nature. The main idea is cognition of oneself through cognition of nature in the spirit of folk philosophy. All aspects of the objective reality are depicted. The surrounding natural landscape shows the Lena River, stone pillars, mountains (myraan), tundra, forests, fields, and valleys. Winter cold and summer heat, birds and animals characterize northern nature. Thus, nature and everything around appear for the Yakut consciousness as a model of the objective reality. The harsh nature strengthens character, will and mind in a person.

This cycle includes aesthetic categories and principles that are similar to Japanese poetry: "seasonal words”, satori, yojo, sabi, avare (yugen), etc.

The idea and figurative components of the works are similar - the beauty of nature is equal to the beauty of life. Admiration for the beauty of nature - avare - is related to the concept of yugen, which denotes an elusive beauty with a touch of mystery. This principle in Utkin's hokku is reflected, for example, in the description of white nights and stargazing, in their connection with the mysterious world of sleep and inaccessibility, the incomprehensibility of the sky.

In addition, a feature of the genre form is an indication of the season, not direct, but indirect: characteristic features of the Yakut spring, winter, etc. For example, a green mountain (myraan) and sprouts, birdsong in the morning indicate spring; heat and sultriness, grasslands indicate summer; migratory birds, lingonberry indicate autumn; bitter frost and fog (tumara) indicate winter.

Typologically similar images are crumbling leaves of trees, dew, and a quiet river. The only difference is that for the Yakuts, birch is closer than maple. Dew is a 
symbol of fleetingness, and a quiet river is a symbol of calmness and tranquility.

Khatyng hahyнnaan Birch in the frost

KYhynyger keste. Has passed into autumn.

Kөmnө丂ө haalla. [8] Fallen leaves remained.

The beauty of the world, the cognition of nature is similar to the self-cognition and can be referred to the category of satori - sudden enlightenment in the ordinary life. Truth can be found in everything that surrounds a person; therefore, a lyrical hero in Yakut hokku strives for unity with nature. The satori motif is found not only in landscape lyrics, but also in the first two cycles by K.D. Utkin. The author seems to call his reader to an instant comprehension of the truth, illumination: comprehend the essence of life, protect culture and environment. This call is accompanied by motives of sadness and regret, which resembles sabi in its definition as noble sorrow.

The poet adheres to makoto - the principle of truth. The world is depicted as it is perceived in order to express the worldview of the people as close as possible to reality.

Knowledge of history and local traditions is needed to read both Japanese and Yakut hokku. Philosophical reflections, allegories and symbolism distinguish the works by K.D. Utkin. Reading the Utkin's hokku requires knowledge of the ideological basis of the Yakut people. Understatement - yojo - is found here. Some emotions, philosophical and life conclusions seem to remain outside the scope of the poem, the reader is given the opportunity to feel the depth of the author's experience and come to a certain conclusion.

The author tries to use a small number of words to express more content and a deep idea. The works by K.D. Utkin are characterized by the aphoristic and laconic character. There are some interesting examples:

Kihi maygyta - The character of a person -

Kestybet kemyhe. His invisible gold.

Orduk da ini. [8] This is supposed to be the best.

Oloh - uchuutal. Life is a teacher.

Sanarbakka yereter. Instructs in silence.

Kihi oнrortuur. [8] Makes a human.

The apparent simplicity and sophistication, sincerity and wisdom, kindness and sensitivity of hokku in the Yakut poet reveal the motives of Matsuo Basho. Civic motives are democratization of the themes of the first two cycles by K.D. Utkin resemble Kobayashi Issa's innovations in the genre of hokku.

The works by the Yakut author adhere to formal, compositional and syllabic canons of the genre form. Of the 88 hokku from the collection, 78 are written according to the canonical rhythm pattern 5-7-5, the remaining 10 amount from 15 to 18 syllables. Of the 264 lines, $171(64.77 \%)$ five-syllable lines, 76 (28.78\%) seven-syllable lines. There are 10 patterns of the rhythmic structure of five-syllable lines, the most widely used patterns are 2-3 (88 times), 3-2 (44 times),
2-1-2 (14 times), 1-2-2 (12 times). Seven-syllable lines have 13 rhythmic patterns. The most numerous are patterns 4-3 (28 times), 2-2-3 (17 times), 3-4 (9), 2-3-2 (8), other patterns occur from 1 to 4 times.

The presence of rhyme and alliteration is a distinctive feature of the genre of hokku in Yakut poetry. Initial alliteration occurs in 48 lines, the depth of consonant words is up to two sounds. Intrapsychological alliteration occurs in $96(36.36 \%)$ lines. There are 33 non-rhymed tercets, in other cases, $a b b$ (31 times), $a a b$ (11 times), aba (9 times), etc. can be observed. There are 111 rhymed lines out of 264.

The national in the works by K.D. Utkin is represented by original imaginative thinking and comparisons, which are rich in cultural concepts and terms. In hokku, a person is traditionally compared to a star; his character is associated with invisible gold; beauty is capable of melting the frozen ground, like the goddess of fertility Aiyysyt; the stages of human growth and maturation are compared with the dimensions of the cult vessel - choron. To reveal the Yakut worldview, the author mentions the national cuisine and utensils as a feature of the material culture of the people. Spirituality and self-awareness are expressed using such concepts as "booth", "tethering" - "serge", "holumtan" - "hearth", "kut" - "soul", "Aiyy" - "holy", "Almighty", "ichchi" - "spirit" and others that reveal the origins, traditions and customs. As one of the features of poetic comparisons and epithets in hokku by K.D. Utkin, a special importance of white should be emphasized. This color in the traditional Yakut worldview is a symbol of beauty, holiness and reverence.

Thus, the first hokku in Yakut poetry was mainly based on traditional features. The studied examples are close to the typology of the original in terms of formal and compositional principles. The poet tries to adhere to the syllabic canon, which can be clearly observed in the works by K.D. Utkin. Hokku in Yakut poetry is implemented in the form of a cycle with a single theme. The connection between the description of nature and the surrounding world and the state of mind of the lyric hero confirms the two-part structure of works. Hokku by K.D. Utkina exhibits a wide range of themes that suggest reflections on the social and moral criteria of human life. In the cycles, the author's originality is expressed in a didactic orientation, motifs of preserving origins and traditions. A general typological similarity between the studied hokku and Japanese poetry lies in adherence to aesthetic principles (yugen, siori, engo, etc.), the use of "seasonal words", vagueness and allegory. Yakut works differ in a special rhyme, the role of alliteration and the national interpretation of images.

\section{Conclusion}

Thus, the national in the works by K.D. Utkin is represented by the material and spiritual components of the Yakut worldview (themes and images). The poems correspond to the canonical features of Japanese hokku, 
mainly rhythm and syllabic canon with the logical scheme 5-7-5. The eastern tradition is expressed in the similarity of the compositional, semantic structure, formal features, and adherence to aesthetic techniques and principles. In tercets by K.D. Utkin, there are similar ideas and figurative components of Japanese verses. Allegories, symbolism, vagueness, the need for knowledge of the traditional culture of the people bring the works closer to Japanese poetry.

\section{References}

1. M.L. Gasparov, Essay on the history of Russian verse: Metrics, rhythm, rhyme, stanza (Fortuna Limited, Moscow, 2000)

2. M.P. Popova, Modern Yakut poetry (19802000s) (Yakutsk University Publishing House, Yakutsk, 2007)

3. M. Hewson, The Debate with Method in the History of Literary Criticism, Comparative literature studies, 55(1), 23-46 (2018)

4. L.S. Mizhit, Triad in Tuvan Literature: Poetic Genre OzhukDazhy (Three-line), $\mathrm{PhD}$ dissertation (Bashkir State University, Ufa, 2007)

5. M.N. Dyachkovskaya, Alliteration and rhyme in Yakut poetry: Problems of evolution and classification (Publishing house of the SB RAS OIGGM, Novosibirsk, 1998)

6. K.D. Utkin, Collection of works: in 16 books. Book 1: Self-choice: the paradigm of the North (Bichik, Yakutsk, 2004)

7. T.N. Vasilieva. The Poetics of solid forms in Yakut lyrics: features of the development of Eastern and European artistic traditions (Science, Novosibirsk, 2011)

8. K.D. Utkin, SymelehsyYtyk (Yakutsk, Bichik, 2006) 